\title{
LITHIUM: PRODUCTION AND ESTIMATED CONSUMPTION. EVIDENCE OF PERSISTENCE
}

Luis A. Gil-Alana ${ }^{1}$, University of Navarra, Pamplona, Spain

and

Manuel Monge, Francisco de Vitoria University (UFV), Madrid, Spain

\begin{abstract}
Understanding the behavior of the lithium supply and the estimated consumption and flows is important for social and economic development. We focus on estimating persistence and for this purpose, we use techniques based on fractional integration. The empirical results provide evidence of mean reversion for the data corresponding to the global lithium production from 1925 to 2014 but not for U.S. lithium-related series such as production (1900 - 2008), estimated consumption (1900 - 2014), imports (1960 2015), and exports $(1971-2015)$.
\end{abstract}

Keywords: Lithium consumption; Lithium production; Fractional integration

JEL Classification: C22; O13; Q21; F01

Comments from the Editor and an anonymous reviewer are gratefully acknowledged.

\footnotetext{
${ }^{1}$ The second-named author gratefully acknowledges financial support from the Ministerio de Economía y Competitividad (ECO2017-85503-R). Comments from the Editor and an anonymous reviewer are gratefully acknowledged.
} 


\section{Introduction}

According to the IPCC (2007), current energy-related greenhouse gas emissions, mainly from fossil fuel combustion account for around $70 \%$ of total emissions. To continue to extract and combust oil, coal, peat, and natural gas at current or increasing rates, and so release carbon into the atmosphere is, as the IEA (2008) stated, environmentally, economically and socially unsustainable.

It is in this scenario that an essential metal, lithium (Li) is being used for next generation technologies, such as energy storage, electric mobility and cordless devices, among others. Lithium is taking on an increasingly strategic role as clean technologies emerge. It is the lightest metal and the least dense solid element. Lithium is a soft, silverwhite metal that belongs to the alkali group of elements. Like all alkali elements, it is highly reactive and flammable. For this reason, it never occurs freely in nature and only appears in compounds, usually ionic compounds. More specifically, lithium carbonate is a lithium compound used in a range of industrial, technical and medical applications. Lithium carbonate is often the first chemical in the production chain, with compounds such as lithium hydroxide being produced with subsequent steps if needed. ${ }^{2}$

Due to their physical and chemical properties, lithium and its compounds have a much-diversified industrial application. According to Jaskula (2017), global end-use markets are estimated as follows: batteries, 39\%; ceramics and glass, 30\%; lubricating greases, $8 \%$; continuous casting mold flux powders and polymer production, $5 \%$ each; air treatment, $3 \%$; and other uses, $10 \%$.

Following Tran and Luong (2015), due to the high demand of lithium for the manufacture of lithium-ion batteries (LiBs), production has increased rapidly over recent years. Lithium consumption for batteries has increased significantly in recent years

\footnotetext{
${ }^{2}$ For this reason, it is also important to see lithium production numbers broken down in terms of lithium carbonate equivalent (LCE).
} 
because rechargeable lithium batteries are used extensively in the growing market for portable electronic devices and are increasingly used in electric tools, electric vehicles, and grid storage applications. ${ }^{2}$ In this article we focus on the statistical properties of various lithium-related historical time series, in particular, focusing on US consumption, production, exports and imports along with world production. We use updated techniques in time series, estimating the order of integration of the series from a fractional viewpoint. In doing so we present a flexible approach to determine if exogenous shocks in the series have transitory or permanent effects depending on such degrees of integration.

\section{Lithium supply and demand}

When assessing the supply of lithium it is important to make a distinction between reserves, resources, production and the impact of recycling. With regard to resources, Jaskula (2016) indicates that global lithium resource mining reached 0.17 millions of tons of LCE, reflecting an increase in lithium mining of over $58 \%$ in the past decade due to its multiple and growing industrial uses. By countries, Jaskula (2017) identified lithium resources in the United States have been revised to 6.9 million tons. In other countries they have been revised to approximately 40 million tons, of which Argentina and Bolivia have approximately 9 million tons each. The major producing countries are: Australia, with more than 2 million tons; Chile, with more than 7.5 million tons; and China, with approximately 7 million tons. Canada's lithium resources are about 2 million tons. The Congo (Kinshasa), Russia and Serbia have resources of approximately 1 million tons each. Lithium resources in Brazil and Mexico account for approximately 200,000 tons each and Austria and Zimbabwe have more than 100,000 tons each.

\footnotetext{
${ }^{2}$ Martin et al. (2017) mention that the most important lithium compound for the production of tradable products is $\mathrm{Li}_{2} \mathrm{CO}_{3}$, with a total quantity of $46 \%$ in 2015 . Of minor, yet growing importance is $\mathrm{LiOH}(19 \%)$. These two lithium compounds cover approximately $2 / 3$ of the market.
} 
The global production of lithium rose steadily from 1994 to 2012 starting at around 128,000 tons and reaching close to 635,000 tons, until the first significant quantitative decrease occurred in 2009, the year of the economic crisis. Subsequently, for the next five years the production volume increased by 61\%. Jaskula (2017) affirms that worldwide lithium production capacity was reported to be 49,400 tons in 2015 ; the capacity utilization was estimated to be $64 \%$ in 2015 and $71 \%$ in 2016 . Worldwide growth will be around $14 \%$, based on average projections by producers and industry analysts (Jascula, 2017).

Figure 1 shows U.S. Geological Survey (USGS) annual global lithium production and the U.S. estimated consumption from 1925 until 2014. Analyzing the available lithium reserves, there are more than 14 million tons, which is 74.5 millions of tons of lithium carbonate equivalent (LCE). (Table 1 shows the available the lithium reserves by countries).

\section{[Insert Figure 1 and Table 1 about here]}

According to Martin et al. (2017), due to huge primary reserves and resources, which can be exploited at fairly low costs, lithium from secondary sources have so far had no significant impact on the total supply. Related to the impact of recycling, Reck and Graedel (2012) indicate that the proportion of recycled lithium is less than $1 \%$ where the potential is in recycling lithium containing batteries. Vikström et al. (2013) affirms that the total production of lithium could potentially increase significantly if higher rates of recycling of used lithium were implemented. Kushnir and Sandén (2012) argue that it is commonly assumed that recycling will come about, enabling recycled lithium to meet a sizable proportion of the demand but they also conclude that the future recycling rate is highly uncertain. Since 2000, global lithium production for use in batteries has increased by approximately $20 \%$ per annum, accounting for $35 \%$ of the overall lithium consumption 
in 2015 (Naumov and Naumova, 2010, and Jaskula, 2016), and Jaskula (2017) cite that worldwide lithium production increased by an estimated $12 \%$ in 2016 in response to increased lithium demand for batteries applications.

\section{[Insert Figure 2 about here]}

When assessing the demand of lithium is important to consider the wide range of applications that it has. Lithium use is currently dominated by the use for batteries (39\%). Primary batteries are single-discharge batteries which feature high charge density, low weight and long life, but are handicapped by high costs per unit. There are also secondary batteries which are rechargeable. The use of Li-ion batteries for electric cars could potentially increase demand significantly. According to Hao et al., (2017) it is expected that increasing global demand for electric vehicles will mean that global lithium consumption will also undergo substantially greater demand over the next few decades.

Vikström et al (2013) mention that as battery size determines the vehicles range, it is likely that the range will continue to increase in the future, which could increase the lithium demand. On the other hand, it is also reasonable to assume that technology will improve, thus reducing the lithium requirements, with a corresponding effect on production. Consequently, understanding the behavior of lithium supply and the estimated consumption and flows is important for social and economic development during the forthcoming decades. For this reason, in this paper, we examine the time series properties of U.S. lithium production from 1900 until 2008, estimated lithium consumption in the U.S. from 1900 until 2014 and global lithium production between 1925 and 2014, using annual data from U.S. Geological Survey. In addition, we also examine US imports and exports data, starting from 1960 and 1971 respectively and ending at 2015. 
As far as the empirical literature is concerned, Ziemann et al. (2012) proposed the first global lithium flow model and found a noticeable discrepancy between production and consumption (Ziemann et al., 2012). Numerous studies investigated the global lithium supply-demand relationship within the context of corresponding lithium-ion battery demand (Habib and Wenzel, 2014; Pehlken et al., 2017; Speirs et al., 2014; Vikström et al., 2013; Chang et al., 2009). Global-level MFA studies have been conducted for many commodities such as aluminum (Liu and Müller, 2013) and copper (Gerst, 2009). Also, many recent papers (Grosjean et al., 2012; Yaksic and Tilton, 2009; and Gruber et al., 2012) consider primarily the available lithium inventory (either as reserves or as resources) and compare this with estimated future consumption volumes, disregarding possible or likely production rates.

This empirical paper tries to fill this gap in the methodology, paying particular attention to transitory shocks (associated with trend stationary processes) and permanent shocks (related to difference stationary processes), focusing on the degree of persistence observed in the series. The contributions of the paper are twofold. First, to our knowledge, this is the first paper that proposes to study the time series properties of lithium production, estimated lithium consumption, global lithium production, and US exports and imports using annual data. Ideally, lithium prices could also be a variable of interest. Unfortunately, we were unable to find appropriate historical prices data to conduct a long memory analysis as the one presented in this work. Thus, in this paper we use some recently developed methods based on the concepts of long run dependence and long memory using fractional integration techniques (Gil-Alana and Hualde, 2009). The methodology used in the second part of the research is similar to the one applied in Monge et al. (2017). As we explain in the following section, fractional integration is more general 
than the standard methods that use exclusively integer orders of differentiation (i.e., AR(I)MA).

The rest of the paper is structured as follows. Section 3 presents the methodology applied in the paper. In Section 4 we discuss the main empirical results, while Section 5 concludes.

\section{Modelling approach}

We use techniques based on long memory and fractional integration. For this purpose we define an integrated process of order 0 or $\mathrm{I}(0)$ as a covariance stationary process with the infinite sum of the autocovariances assumed to be finite. Alternatively, in the frequency domain, an $\mathrm{I}(0)$ process can be defined as a process with a spectral density function that is positive and finite at the zero frequency. This is a very broad definition that includes not only the white noise model but also weakly autocorrelated structures such as the one produced by the stationary and invertible AutoRegressive Moving Average (ARMA) form. On the other extreme, we can have a nonstationary process, defined as having a unit root or integrated of order 1, i.e., I(1), which, in its simplest form, is the random walk model of the form:

$$
(1-B) x_{t}=u_{t}, \quad t=1,2, \ldots
$$

where $B$ is the backshift operator $\left(B x_{t}=x_{t-1}\right)$ and $u_{t}$ is $I(0)$. Note that if $u_{t}$ is an ARMA(p, q) process, $x_{t}$ is then an $\operatorname{ARIMA}(p, 1, q)$ process. However, the stationary $I(0)$ and the nonstationary I(1) cases are both particular cases within a more flexible type of model known as fractionally integrated or $\mathrm{I}(\mathrm{d})$ where $\mathrm{d}$ can be any real value. Thus, we consider a model of form

$$
(1-B)^{d} x_{t}=u_{t}, \quad t=1,2, \ldots,
$$


where $u_{t}$ is $\mathrm{I}(0)$ and $d$ can be 0 , a value between 0 and 1,1 , or even above $1 .^{3}$

Processes such as (2) with $\mathrm{d}>0$ belong to a broader category named long memory which is characterized because the infinite sum of the autocorrelation is infinite, or, alternatively, in the frequency domain, because the spectral density function has a singularity at the smallest, zero, frequency. They were originally proposed by Granger (1980, 1981), Granger and Joyeux (1980) and Hosking (1981), based on the observation that many economic aggregate time series presented an extremely large value in the estimated spectrum at the smallest frequency, consistent with first differentiation, but once the series were differenced, the estimated spectrum displayed a value closer to zero at the zero frequency, which was a clear indication of overdifferentation. The I(d) models with fractional values of $d$ became very popular in the late nineties throughout the works of Baillie (1996), Gil-Alana and Robinson (1997), Silverberg and Verspagen (1999) and others, and they have also been employed more recently in the analysis of various metals and products by authors such as Panas (2001), Arouri et al. (2012), Gil-Alana and Tripathy (2014) and Gil-Alana et al. (2015) among many others.

We estimate the differencing parameter $d$ by using both parametric and semiparametric techniques. Dealing with the parametric methods we use the Whittle function in the frequency domain as proposed in Dahlhaus (1989) and we implement it through the tests of Robinson (1994). Semiparametric methods, based on local Whittle methods (Robinson, 1995, Shimotsu and Phillips, 2006) will also be implemented in the paper.

Note that the estimation of $d$ is crucial from different fronts. From a statistical viewpoint $\mathrm{x}_{\mathrm{t}}$ is covariance stationary as long as $\mathrm{d}$ is smaller than 0.5 , while it is nonstationary for $d \geq 0.5$ in the sense that the partial sums increase in magnitude with $d$.

\footnotetext{
${ }^{3}$ See, Gil-Alana and Hualde, 2009 for a review of these models.
} 
However, the differencing parameter $\mathrm{d}$ is also important from an economic viewpoint. Thus, if $\mathrm{d}$ is smaller than 1 , shocks will have a transitory nature and their effects will disappear by themselves in the long run, contrary to what happens if $d \geq 1$ where shocks are not mean reverting and persist forever. Thus, $\mathrm{d}$ can be viewed as an indicator of the degree of persistence, the higher its value is, the higher the degree of persistence is in the data.

\section{Data and empirical results}

The data examined in this work correspond to U.S. lithium production from 1900 until 2008, the estimated lithium consumption in the U.S. from 1900 to 2014, the global lithium production from 1925 to 2014 , and the US imports (1960 - 2015) and exports (1971 2015), using annual data. The dataset was obtained from the United States Geological Survey. The data used are standardized to metric tons $(\mathrm{t})$ and dollars per metric ton $(\$ / \mathrm{t})$ to allow for data comparison between mineral commodities through time.

From an econometric perspective we first consider the model given by (1) and (2), i.e.,

$$
\mathrm{y}_{\mathrm{t}}=\beta_{0}+\beta_{1} \mathrm{t}+\mathrm{x}_{\mathrm{t}} ; \quad(1-\mathrm{B})^{\mathrm{d}} \mathrm{x}_{\mathrm{t}}=\mathrm{u}_{\mathrm{t}}, \quad \mathrm{t}=0,1, \ldots
$$

under the assumption that the error term, $\mathrm{u}_{\mathrm{t}}$, is uncorrelated. We display in Table 2 the estimates of $d$ in (3) using the Whittle function in the frequency domain (Dahlhaus, 1989) for the three standard cases of i) no deterministic terms (i.e., when both coefficients $\beta_{0}$ and $\beta_{1}$ are assumed to be zero), ii) with a constant (i.e., imposing that $\beta_{1}$ is equal to zero), and iii) with a linear time trend (both coefficients unknown).

\section{[Insert Tables 2 and 3 about here]}

The first thing we observe in Table 2 is that the time trend is not required in the cases of "U.S. production", "U.S. exports" and "U.S. imports", but it is for the other two 
series ("U.S. consumption" and "global production"). Focusing on the estimated values of d, we note that they are 0.91 and 0.85 respectively for "U.S. production" and "U.S. consumption", and 0.97 and 0.84 respectively for "U.S. exports" and "U.S. imports", and the unit root null hypothesis cannot be rejected in either of the four cases. However, for "global production", the estimated value of $\mathrm{d}$ is 0.70 and the $\mathrm{I}(1)$ hypothesis is now decisively rejected in favor of mean reversion $(d<1)$, noting that the upper value of the confidence band is strictly smaller than 1 . Thus, exogenous shocks affecting this series will disappear by themselves in the long run, contrary to what happens to the other two series. Table 3 displays the estimated coefficients for each series.

\section{[Insert Tables 4 and 5 about here]}

Next we allow for autocorrelated errors in $u_{t}$ in (3) and the results are displayed in Tables 4 and 5. However, instead of imposing a simple autoregressive (AR) model, which may be problematic based on the large degree of persistence observed in the previous tables, we use here a non-parametric approach due to Bloomfield (1973) that approximates the behavior of ARMA structures with very few parameters. This model is exclusively defined in terms of its spectral density function but produces autocorrelations decaying exponentially as in the AR case. Using this approach, the estimated values of $\mathrm{d}$ are reported in Table 4. First, we notice that the time trend is now required in the first three series (US consumption and production and world production) but not for the US exports and imports, and the estimated values of $\mathrm{d}$ are $0.83,0.76$ and 0.35 respectively for "U.S. production", "U.S. consumption" and "global production", and 0.97 and 0.85 for "U.S. exports" and "U.S. imports" respectively. Interestingly, and consistent with the previous tables, the I(1) hypothesis cannot be rejected in either of the series with the exception of "global production", where it is rejected in favor of mean reversion, and the estimated value of $d$ is now much smaller than in the case of white noise errors. 


\section{[Insert Table 6 about here]}

Finally, and as a robustness method, we also estimate d using a semiparametric method, where no functional form is imposed on the error term. We use here a "local" Whittle approach, initially developed by Robinson (1995) and later improved by Velasco (1999), Shimotsu and Phillips (2006), Abadir et al. (2007) and others. This method requires the selection of a bandwidth number, and we have chosen the value $m=8,9,10$, 11 and 12 . Given the nonstationary nature of the data, we obtain the results based on the first differenced data, then adding 1 to the estimated values. The results are displayed in Table 6. We see that, once more, they are consistent with the parametric ones. The I(1) hypothesis cannot be rejected for any of the US series: "U.S. production", "U.S. consumption", "U.S. exports" and "U.S. imports", and this hypothesis is rejected in favor of $\mathrm{d}<1$ in the case of "global production" implying mean reverting behavior for the latter series. Thus, the results seem to be robust across the different methodologies used.

\section{Concluding comments}

In this article, our objective and focus have been first to analyze the statistical properties of U.S. lithium production from 1900 until 2008, the estimated lithium consumption in the U.S. from 1900 to 2014, the global lithium production (1925 - 2014), U.S. lithium imports (1960 - 2015) and exports (1971 - 2015), with annual data, and using fractional integration or $\mathrm{I}(\mathrm{d})$ methods. In doing so we have tried to gain a deeper understanding of the behavior of lithium from a time series perspective, investigating the nature of exogenous shocks in the series by looking at their orders of integration.

We first employed parametric methods and, imposing an uncorrelated (white noise) process for the d-differenced series, the estimated values of $d$ were $0.91,0.85$ and 0.70 respectively for U.S. lithium production, U.S. estimated consumption and global 
lithium production; for U.S. exports and imports the values of d were respectively 0.97 0.84 . The unit root null hypothesis (i.e., $d=1$ ) could not be statistically rejected in any of the series except for the world production, supporting thus the hypothesis of no mean reversion and permanency of the shocks. The contrary happens for global production where the unit root hypothesis was rejected in favor of mean reversion $(\mathrm{d}<1)$ and thus implying transitory shocks.

Using autocorrelated disturbances throughout the exponential spectral model of Bloomfield (1973) the same conclusion holds though the estimated value of $d$ for the global lithium production is now much smaller (0.35). Using a "local" Whittle semiparametric approach, once more, the same conclusions hold: the I(1) hypothesis cannot be rejected for any of the U.S. lithium related series but it is decisively rejected in favor of mean reversion for the global lithium production. Thus, the results are fairly robust across the different implemented methods.

An interesting conclusion of these results is that in the event of negative shocks affecting the series, special attention should be paid to U.S. lithium production and U.S. estimated consumption but not to global production since, in the latter case, the series will return by itself to its original trend, unlike what happens in the U.S. case. The contrary occurs in the case of positive shocks since special attention should then be paid to global production to make that change permanent, while in the U.S. the change does seem to be permanent.

The results presented in this paper may help to gain a better understanding of the dynamic behavior of lithium production and estimated consumption. Moreover, they can help to understand the lithium industry and the effect of the shocks on this product. Furthermore, these results may be relevant for commodities analysts and financialmacroeconomic forecasters, noting that the fractional integration approach outperforms 
the classical methods based on integer orders of differentiation by including them as particular cases of interest and then allowing for higher flexibility in the dynamic specification of the series. 


\section{References}

Abadir, K.M., W. Distaso and L. Giraitis. 2007. Nonstationarity-extended local Whittle estimation, Journal of Econometrics, 141, 1353-1384.

Arouri, M. E. H., Hammoudeh, S., Lahiani, A., \& Nguyen, D. K. 2012. Long memory and structural breaks in modeling the return and volatility dynamics of precious metals. The Quarterly Review of Economics and Finance, 52, 207-218.

BP Energy Outlook. 2017. https://www.bp.com/content/dam/bp/pdf/energyeconomics/energy-outlook-2017/bp-energy-outlook-2017.pdf.

Baillie, R.T. (1996), Long memory processes and fractional integration in econometrics, Journal of Econometrics 73, 5-59.

Bloomfield, P. 1973. An exponential model in the spectrum of a scalar time series. Biometrika, 60, 217-226.

Chang, T. C., You, S. J., Yu, B. S., Yao, K. F. 2009. A material flow of lithium batteries in Taiwan. Journal of Hazardous Materials, 163, 910-915.

Dahlhaus, R. (1989) Efficient Parameter Estimation for Self-Similar Process. Annals of Statistics, 17, 1749-1766.

Gerst, M.D. 2009. Linking material flow analysis and resource policy via future scenarios of In-use stock: an example for copper. Environmental Science and Technology, 43, 6320-6325.

Gil-Alana, L.A., Hualde, J. 2009. Fractional integration and cointegration. An overview with an empirical application. The Palgrave Handbook of Applied Econometrics, 2, 434472 .

Gil-Alana, L.A. and P.M. Robinson (1997), Testing of unit roots and other nonstationary hypotheses in macroeconomic time series, Journal of Econometrics 80, 241-268.

Gil-Alana, L. A., Tripathy, T. 2014. Modelling volatility persistence and asymmetry: A Study on selected Indian non-ferrous metals markets. Resources Policy, 41, 31-39.

Gil-Alana, L. A., Chang, S., Balcilar, M., Aye, G. C., \& Gupta, R. 2015. Persistence of precious metal prices: A fractional integration approach with structural breaks. Resources Policy, 44, 57-64.

Granger, C.W. J. 1980. "Long memory relationships and the aggregation of dynamic models", Journal of Econometrics, 14, 227-238.

Granger, C. W. J. 1981. "Some properties of time series data andvtheir use in econometric model specification", Journal of Econometrics,16, 121-130.

Granger, C. W. J. \& R. Joyeux 1980. "An introduction to long memory time series and fractionally differencing", Journal of Time Series Analysis, 1, 15-29. 
Hosking, J. R. M. 1981. "Modelling persistence in hydrological time series using fractional differencing", Water Resources Research,20, 1898-1908.

Grosjean C, Miranda PH, Perrin M, Poggi P. 2012. Assessment of world lithium resources and consequences of their geographic distribution on the expected development of the electric vehicle industry. Renewable and Sustainable Reviews, 16, 1735-1744.

Gruber P, Medina P, Keoleian G, Kesler S, Everson M, Wallington T. 2012. Global lithium availability, a constraint for electric vehicles? Journal of Industrial Ecolology, 15, 760-775.

Habib, K., Wenzel, H. 2014. Exploring rare earths supply constraints for the emerging clean energy technologies and the role of recycling. Journal of Cleaner Production, 84, 348-359.

Hao, H., Liu, Z., Zhao, F., Geng, Y., Sarkis, J. 2017. Material flow analysis of lithium in China. Resources Policy, 51, 100-106.

IEA. g Energy Outlook 2008. http://www.iea.org.

IPCC fourth assessment report: mitigation of climate change; 2007. http://www.ipcc.ch/pdf/assessment-report/ar4/wg3/ar4-wg3-chapter5.pdf.

Jaskula, B.W. 2016. Mineral Commodity Summaries - Lithium 2016. U.S. Geological Survey.

Jaskula, B.W. 2017. Mineral Commodity Summaries - Lithium 2017. U.S. Geological Survey.

Kushnir, D., Sandén, B. A. 2012. The time dimension and lithium resource constraints for electric vehicles. Resources Policy, 37, 93-103.

Liu, G., Müller, D. B. 2013. Mapping the global journey of anthropogenic aluminum: A trade-linked multilevel material flow analysis. Environmental science \& technology, 47, 11873-11881.

Martin, G., Rentsch, L., Hoeck, M., Bertau, M. 2017. Lithium market research-global supply, future demand and price development. Energy Storage Materials, 6, 171-179.

Monge, M., Gil-Alana, L. A., de Gracia, F. P. 2017. Crude oil price behaviour before and after military conflicts and geopolitical events. Energy, 120, 79-91.

Naumov, A. V., Naumova, M. A. 2010. Modern state of the world lithium market. Russian Journal of Non-Ferrous Metals, 51, 324-330.

Panas, E. 2001. Long memory and chaotic models of prices on the London Metal Exchange. Resources Policy, 27, 235-246. 
Pehlken, A., Albach, S., Vogt, T. 2017. Is there a resource constraint related to lithium ion batteries in cars?. The International Journal of Life Cycle Assessment, 22, 40-53.

Reck, B. K., Graedel, T. E. 2012. Challenges in metal recycling. Science, 337, 690-695.

Robinson, P.M. (1994) Efficient tests of nonstationary hypotheses, Journal of the American Statistical Association 89, 1420-1437.

Robinson, P.M. (1995) Gaussian semi-parametric estimation of long range dependence, Annals of Statistics 23, 1630-1661.

Shimotsu, K., Phillips, P. C. 2006. Local Whittle estimation of fractional integration and some of its variants. Journal of Econometrics, 130, 209-233.

Silverberg, G. and B. Verspagen (1999). Long memory in time series of economic growth and convergence, Eindhoven Center for Innovation Studies, Working Paper 99.8.

Speirs, J., Contestabile, M., Houari, Y., Gross, R. 2014. The future of lithium availability for electric vehicle batteries. Renewable and Sustainable Energy Reviews, 35, 183-193.

Tran, T., Luong, V. T. 2015. Lithium Production Processes. Lithium Process Chemistry, 81-124.

Velasco, C. (1999) Gaussian Semiparametric Estimation of Non-stationary Time Series, Journal of Time Series Analysis 20, 1, 87-127.

Vikström, H., Davidsson, S., Höök, M. 2013. Lithium availability and future production outlooks. Applied Energy, 110, 252-266.

Yaksic, A., Tilton, J. E. 2009. Using the cumulative availability curve to assess the threat of mineral depletion: The case of lithium. Resources Policy, 34, 185-194.

Ziemann, S., Weil, M., Schebek, L. 2012. Tracing the fate of lithium. The development of a material flow model. Resources, Conservation and Recycling, 63, 26-34. 


\begin{tabular}{|c|c|}
\hline Table 1. Lithium Wor & d Reserves \\
\hline Country & Reserves \\
\hline United States & 38.000 \\
\hline Argentina & 2.000 .000 \\
\hline Australia & 1.600 .000 \\
\hline Brazil & 48.000 \\
\hline Chile & 7.500 .000 \\
\hline China & 3.200 .000 \\
\hline Portugal & 60.000 \\
\hline Zimbabwe & 23.000 \\
\hline World total (rounded) & 14.000 .000 \\
\hline
\end{tabular}

Figure 1. Annual world lithium production vs U.S. estimated consumption (USGS 1925-2014)

WORLD PRODUCTION VS ESTIMATED CONSUMPTION

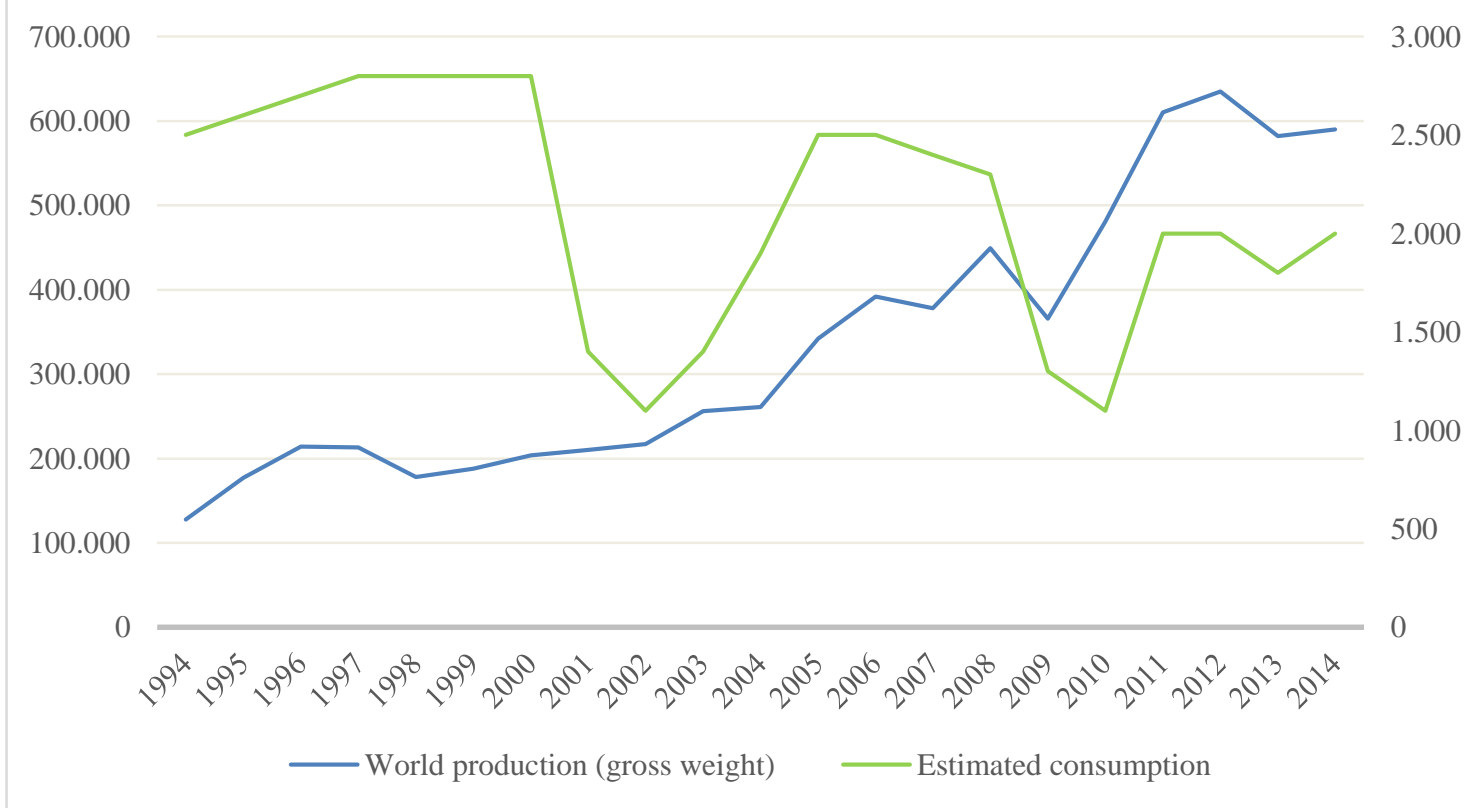


Figure 2. Main lithium uses according to USGS (2017), in relative percentages of Li metal equivalent used.

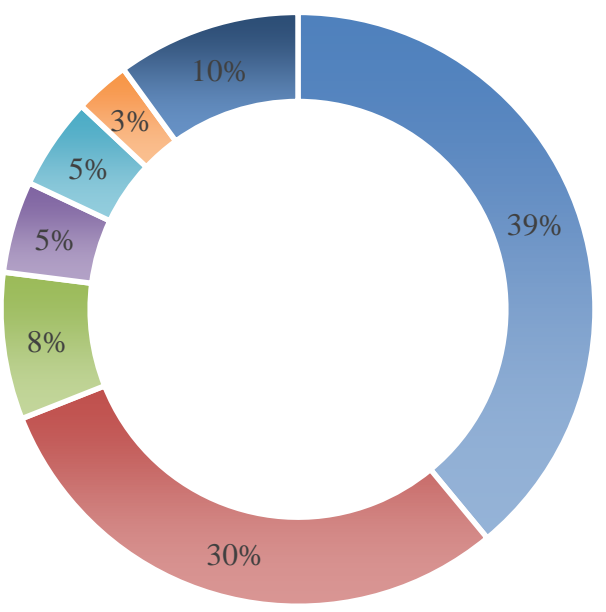

- Lithium batteries

- Ceramic and glass

- Greases

- Casting mold flux powders

- Polymer production

- Air treatment

- Others 
Table 2: Estimates of $\mathrm{d}$ and 95 confidence bands with no autocorrelated errors

\begin{tabular}{|c|c|c|c|}
\hline & No terms & A constant & A linear time trend \\
\hline U.S. PRODUCTION & $0.92 \quad(0.77,1.13)$ & $0.91(0.80,1.07)$ & $0.91 \quad(0.80,1.07)$ \\
\hline U.S. CONSUMPTION & $0.99(0.73,1.11)$ & $0.85(0.74,1.02)$ & $0.85(0.74,1.02)$ \\
\hline WORLD PROD. & $0.88 \quad(0.73,1.09)$ & $0.74 \quad(0.63,0.94)$ & $0.70 \quad(0.54, \quad 0.94)$ \\
\hline EXPORTS & $1.09(0.88,1.45)$ & $1.02(0.77,1.41)$ & $1.02(0.81,1.39)$ \\
\hline IMPORTS & $0.63(0.52,0.81)$ & $0.67 \quad(0.57,0.85)$ & $0.60 \quad(0.44, \quad 0.83)$ \\
\hline
\end{tabular}

In bold, the most adequate specification in relation to the deterministic terms.

Table 3: Estimated coefficients with no autocorrelated errors

\begin{tabular}{|c|c|c|c|}
\hline & d $(95 \%$ band $)$ & Constant & Time trend \\
\hline U.S. PRODUCTION & $0.91 \quad(0.80,1.07)$ & $2.43111 \quad(5.01)$ & ---- \\
\hline U.S. CONSUMPTION & $0.85 \quad(0.74,1.02)$ & $2.30083 \quad(5.24)$ & $0.04774 \quad(2.11)$ \\
\hline WORLD PROD. & $0.70 \quad(0.54,0.94)$ & $8.05151 \quad(16.08)$ & $0.05951 \quad(3.40)$ \\
\hline EXPORTS & $1.02(0.77,1.41)$ & $583.8273 \quad(2.17)$ & ----- \\
\hline IMPORTS & $0.60(0.44,0.83)$ & $437.9187(2.05)$ & \\
\hline
\end{tabular}

Table 4: Estimates of $d$ and 95 confidence bands with autocorrelated errors

\begin{tabular}{|c|c|c|c|}
\hline & No terms & A constant & A linear time trend \\
\hline U.S. PRODUCTION & $0.64 \quad(0.48,0.97)$ & $0.85(0.71,1.08)$ & $0.83 \quad(0.66,1.08)$ \\
\hline U.S. CONSUMPTION & $0.58 \quad(0.44, \quad 0.90)$ & $0.79(0.66,1.00)$ & $0.76(0.59,1.01)$ \\
\hline WORLD PROD. & $0.67 \quad(0.40,1.04)$ & $0.58 \quad(0.47,0.78)$ & $0.35 \quad(0.11,0.71)$ \\
\hline EXPORTS & $0.92(0.53,1.38)$ & $0.97 \quad(0.11,1.53)$ & $0.98 \quad(0.32,1.44)$ \\
\hline IMPORTS & $0.59(0.35,1.06)$ & $0.85(0.65,1.11)$ & $0.83 \quad(0.56,1.11)$ \\
\hline
\end{tabular}

In bold, the most adequate specification in relation to the deterministic terms.

Table 5: Estimated coefficients with autocorrelated errors

\begin{tabular}{|c|c|c|c|}
\hline & d $(95 \%$ band $)$ & Constant & Time trend \\
\hline U.S. PRODUCTION & $0.83 \quad(0.66,1.08)$ & $2.40408 \quad(5.02)$ & $0.04260 \quad(1.86)$ \\
\hline U.S. CONSUMPTION & $0.76 \quad(0.59,1.01)$ & $2.41701 \quad(5.51)$ & $0.04903 \quad(3.16)$ \\
\hline WORLD PROD. & $0.35 \quad(0.11,0.71)$ & $7.77846 \quad(21.57)$ & $0.06273 \quad(9.21)$ \\
\hline EXPORTS & $0.97 \quad(0.11,1.53)$ & $6.36054 \quad(34.64)$ & ----- \\
\hline IMPORTS & $0.85(0.65,1.11)$ & $6.58477 \quad(9.55)$ & ----- \\
\hline
\end{tabular}


Table 6: Estimates of $\mathbf{d}$ based on a "local" Whittle semiparametric method

\begin{tabular}{|c|c|c|c|c|c|}
\hline & 8 & 9 & 10 & 11 & 12 \\
\hline U.S. PRODUCTION & 0.955 & 0.979 & 1.005 & 1.002 & 1.017 \\
\hline U.S. CONSUMPTION & 0.960 & 0.893 & 0.919 & 0.935 & 0.938 \\
\hline WORLD PROD. & $\mathbf{0 . 5 0 4}$ & $\mathbf{0 . 5 7 9}$ & $\mathbf{0 . 7 6 2}$ & $\mathbf{0 . 6 7 5}$ & $\mathbf{0 . 7 2 2}$ \\
\hline EXPORTS & 1.080 & 1.126 & 1.161 & 1.144 & 1.115 \\
\hline IMPORTS & 0.967 & 0.813 & 0.814 & 0.822 & 0.839 \\
\hline \hline Lower 95\% I(1) & 0.689 & 0.709 & 0.725 & 0.739 & 0.752 \\
\hline Upper 95\% I(1) & 1.310 & 1.290 & 1.274 & 1.260 & 1.247 \\
\hline
\end{tabular}

In bold, statistical evidence of mean reversion $(\mathrm{d}<1)$ at the $5 \%$ level. 